\title{
北秦岭元古宙基性岩的高放射成因 铅同位素组成的发现及其意义*
}

许继锋张本仁韩吟文

(中国地质大学地球科学学院, 武汉 430074)

\section{关键词基性岩 铅同位素 元古宙 北泰岭}

秦岭造山带分隔着中国南北大陆, 这两个陆块在地质历史时期可能分别是冈瓦纳与劳亚 大陆的一部分. 因此, 研究秦岭造山带可对两个大陆的分界作出限定. 秦岭造山带可分为北 秦岭和南秦岭构造单元, 它们曾被认为分别是华北陆块和扬子陆块的大陆边缘 ${ }^{[1,2]}$. 若北秦 岭确是华北陆块的大陆边缘, 它们应具有相同的组成. 近年来的研究表明, 岩石的铅同位素组 成存在明显的“块体效应”,不同的陆块具有不同的铅同位素组成 ${ }^{[3,4]}$. 本文通过研究北秦岭 地区元古宙基性岩的铅同位素组成并与两侧陆块相同时代的基性岩作对比, 发现北秦岭地区 的岩石不同于两侧陆块且具有独特的高放射成因铅同位素组成特征, 它是华北陆块与扬子陆 块的分界(带), 据此本文还讨论了北秦岭的归属及其与秦岭古洋的关系等.

\section{1 北秦岭元古宙基性岩的铅同位素组成}

夹持于商丹琏合带与栾川 - 黑沟断裂之间、位于华北陆块南侧的狭长状地带被称为北秦 岭地区. 该地区主要出露的元古宙岩群构成了北秦岭基底, 它们分别是古元古代秦岭群; 中元 古代宽坪群; 新元古代丹凤群及二郎坪群(它们中的部分可能属于早古生代). 其中秦岭群广 泛分布于北秦岭地区的中部, 宽坪群和二郎坪群位于其北侧, 丹凤群居其南侧. 在这些岩群 中, 广泛存在变质的基性岩类, 尽管它们经历过绿片岩相-角闪岩相的变质, 但前人的研究已证 明它们大多为变质的火山岩或相近时代的侵入岩 ${ }^{[5 \sim 7]}$. 在北秦岭南侧的南秦岭地区, 元古宙 陡岭群、佛坪群、武当群和耀岭河群中都分布有基性的火成岩类; 在北秦岭北侧的华北陆块南 缘, 元古宙安沟群与熊耳群中也出现有基性火山岩.

北秦岭及邻区元古宙基性岩的铅同位素比值的范围和平均值列于表 1 中. 对比 3 个构造 单元上相近时代的基性岩, 北秦岭地区的基性岩具有明显高的铀铅与针铅同位素比值; 南秦岭 地区基性岩其次; 华北陆块南缘基性岩具有较低的铅同位素比值, 它们的铅同位素比值表现出 中间高、两侧低的地理分布特征. 北秦岭基性岩的高铅同位素比值在图 1 中也得到明显的显 示. 它们的这种组成明显不同于华北陆块上各类岩石(新生代玄武岩、太古宙基性麻粒岩、矿 石和花岗石等)较低的铅同位素比值特征; 而与华南地区岩石的铅同位素比值相似, 具有较

1995-12-15 收稿, 1996-03-08 收修改稿

* 国家自然科学基金资助项目 
表 1 北秦岭及邻区元古宙基性岩及花岗岩长石等的铅同位素组成

\begin{tabular}{|c|c|c|c|c|c|c|c|}
\hline 地区 & 岩群 & 时代 & 样品数 & ${ }^{206} \mathrm{~Pb} /{ }^{204} \mathrm{~Pb}$ & ${ }^{207} \mathrm{~Pb} /{ }^{204} \mathrm{~Pb}$ & ${ }^{208} \mathrm{~Pb} /{ }^{204} \mathrm{~Pb}$ & 备注") \\
\hline \multirow{4}{*}{ 南 } & 陡岭群 & Pt1 & 3 & $16.369 \sim 18.132$ & $15.271 \sim 15.581$ & $36.239 \sim 38.166$ & 1 \\
\hline & & 平均值 & 17.431 & 15.460 & 37.550 & & \\
\hline & 佛坪群 & Pt1 & 2 & $17.645 \sim 18.034$ & $15.418 \sim 15.530$ & $37.671 \sim 38.290$ & 1 \\
\hline & & & 平均值 & 17.840 & 15.474 & 37.980 & \\
\hline \multirow[t]{4}{*}{ 秦 } & 武当群 & Pt2 & 7 & $17.642 \sim 18.136$ & $15.366 \sim 15.607$ & $36.611 \sim 38.249$ & 1,2 \\
\hline & & & 平均值 & 17.485 & 15.485 & 37.624 & \\
\hline & 耀岭河群 & $\mathrm{Pt} 2 \sim 3$ & 11 & $17.206 \sim 18.278$ & $15.436 \sim 15.552$ & $37.909 \sim 38.9 ? 0$ & 3 \\
\hline & & & 平均值 & 17.775 & 15.470 & 38.407 & \\
\hline \multirow[t]{2}{*}{ 岭 } & 花岗岩长石 & $\mathrm{P}+3$ & 3 & $17.298 \sim 17.416$ & $15.400 \sim 15.528$ & $37.298 \sim 37.536$ & 7 \\
\hline & & & 平均值 & 17.330 & 15.450 & 37.466 & \\
\hline \multirow{4}{*}{ 北 } & 秦岭群 & Pt1 & 7 & $17.063 \sim 19.098$ & $15.426 \sim 15.606$ & $37.421 \sim 38.598$ & 1,4 \\
\hline & & 平均值 & 18.360 & 15.603 & 38.021 & & \\
\hline & 宽坪群 & $P+2$ & 2 & $18.756 \sim 18.793$ & $15.756 \sim 15.791$ & $38.967 \sim 39.243$ & 1 \\
\hline & & & 平均值 & 18.775 & 15.774 & 39.115 & \\
\hline \multirow[t]{4}{*}{ 秦 } & 丹凤群 & $\mathrm{Pt} 3 \sim \mathrm{Pz}$ & 10 & $18.011 \sim 19.053$ & $15.419 \sim 15.594$ & $37.840 \sim 38.337$ & 5 \\
\hline & & & 平均值 & 18.366 & 15.536 & 38.101 & \\
\hline & 二郎坪群 & $\mathrm{Pt} 3 \sim \mathrm{Pz}$ & 4 & $18.156 \sim 18.421$ & $15.508 \sim 15.566$ & $38.147 \sim 38.676$ & 1,6 \\
\hline & & & 平均值 & 18.250 & 15.543 & 38.420 & \\
\hline \multirow[t]{2}{*}{ 岭 } & 花岗岩长石 & $\mathrm{Pt} 3$ & 4 & $18.221-18.350$ & $15.601 \sim 15.615$ & $38.309 \sim 38.345$ & 7 \\
\hline & & & 平均值 & 18.280 & 15.607 & 38.327 & \\
\hline 华北 & 安沟群 & Pt1 & 2 & $15.907 \sim 16.345$ & $15.234 \sim 15.296$ & $36.005 \sim 36.193$ & 1 \\
\hline 陆块 & & & 平均值 & 16.126 & 15.265 & 36.099 & \\
\hline \multirow[t]{2}{*}{ 南缘 } & 熊耳群 & $\mathrm{Pt} 2$ & 2 & $15.704 \sim 16.853$ & $15.231 \sim 15.368$ & $35.776 \sim 36.317$ & 1 \\
\hline & & & 平均值 & 16.279 & 15.300 & 36.047 & \\
\hline 松树沟 & & $983 \sim 1030$ & 5 & $18.054 \sim 18.660$ & $15.538 \sim 15.632$ & $37.770 \sim 38.493$ & 1 \\
\hline 蛇绿岩 & & $\mathrm{Ma}$ & 平均值 & 18.379 & 15.587 & 38.176 & \\
\hline
\end{tabular}

a) 1. 本文;2. 陈晋锺等 ${ }^{[9]} ; 3$. 王寿琼 (1994), 内部报告; 4. 胡鹏云 $(1990)$, 转引文献 [4];5. 张旗 ${ }^{[7]} ; 6$. 张珠福 (1995), 博士论文;7. 张宏飞(1996), 出版中. $\mathrm{Pt}$ 一一元古宙; $\mathrm{Pz}$ 一古生代

高的铅同位素比值. 北秦岭元古宙基性岩相对两侧的南秦岭和华北陆块南缘的高放射成因铅 同位素组成, 是否与基性岩浆混染了地壳物质有关? 秦岭群的片麻岩与大理岩等确有高的铅 同位素比值 ${ }^{[4], 1)}$, 但基性岩的钕同位素组成与混染的结论不相吻合, 秦岭群基性岩 (1967 Ma) 的 $\varepsilon_{\mathrm{Nd}}(t)$ 高达 +7.2 ; 宽坪群基性岩 (1 $\left.142 \mathrm{Ma}\right)$ 的 $\varepsilon_{\mathrm{Nd}}(t)$ 为 $4.2 \sim 6.6$; 丹凤群基性岩( $900 \sim$ $1000 \mathrm{Ma}$ )、二郎坪群基性岩 $(788 \sim 822 \mathrm{Ma}), \varepsilon_{\mathrm{Nd}}(t)$ 分别在 $4.9 \sim 7.3$ 和 $3.7 \sim 6.3$ 之间 $^{[8]}$ 变 化,这些基性岩高的 $\varepsilon_{N d}(t)$ 值证明它们没有陆壳混染或混染作用是不重要的. 另外, 由于上 述岩群都经历了不同程度的变质, 是否是不同的变质程度造成了北秦岭基性岩与两侧基性岩 铅同位素组成的差异呢? 北秦岭的秦岭群与形成时代相近的南秦岭陡岭群、华北陆块南缘的 安沟群, 都达到了绿片岩一角闪岩相的变质程度: 北秦岭的宽坪群、丹凤群和二郎坪群与南秦 岭的武当群、耀岭河群的变质程度也是相近的, 仅华北陆块南缘熊耳群变质较浅, 因而变质作 用可能不会造成这些基性岩铅同位素组成区域性的差异; 又由于对比的是近相同时代的岩石, 它们形成之后的原地放射性衰变是相似的, 秦岭少数基性岩有铀、针、铅丰度值, 据此计算它们

1)游振东。科研报告, 1987 

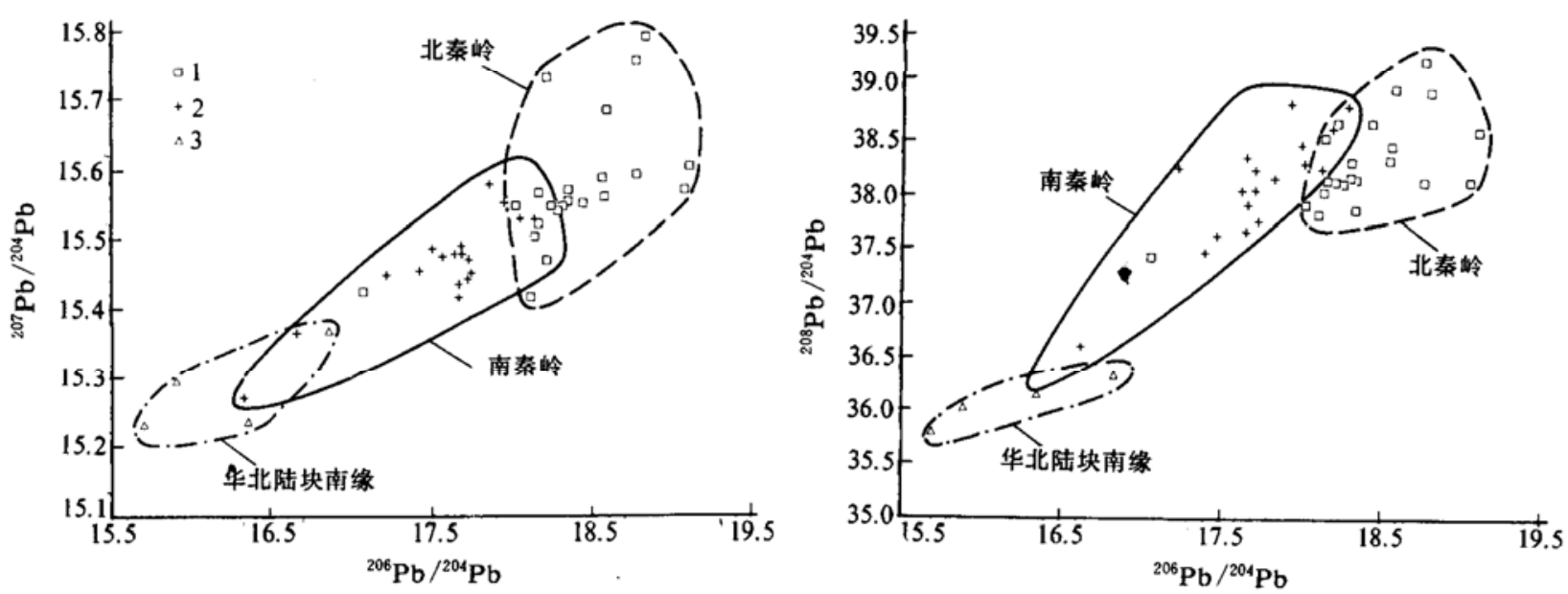

图 1 北名的、南䅈岭及华北陆块南缘正古宙基性岩铅问位系的对比

1一一北秦岭基性岩, 2- 一南秦岭基性岩, 3- - 华北陆块南缘基性岩

形成时的初始值 ${ }^{1}$, 北秦岭仍高于南秦岭的基性岩; 长石的铅同位素比值可代表其形成时的特 征, 源于北秦岭基底的新元古代花岗岩的长石铅也表现出相同的高放射成因铅同位素比值,也 高于南秦岭新元古代花岗岩的长石 (表 1), 说明新元古代时北秦岭具高放射成因铅同位素特 征. 因此, 虽然目前还不能确切知道变质作用和后期放射性积累对基性岩铅同位素的比值有 多大的影响, 但北秦岭岩石的高放射成因铅同位素组成及其与两侧陆块基性岩的差异可能确 实存在,不同构造单元基性岩组成的差异应该反映了它们形成时的铅同位素初始比值的不同.

\section{2 讨论}

北秦岭地区曾被认为是华北陆块的南部大陆边缘, 本文的资料不能支持这一结论. 据研 究 $^{[2]}$, 北秦岭地区地壳基底主要是在元古宙增生形成的, 元古宙基性岩是其地壳基底的组成 部分, 它们与华北陆块南缘时代相近的基性岩铅同位素组成有明显差异, 表明它们分属不同的 幔壳域. 因而, 北秦岭与华北陆块元古宙地幔源区和地壳基底组成是不同的,应归属于不同的 地块(或陆块), 北秦岭在元古宙时可能不是华北陆块的南部大陆边缘.

作者对秦岭蛇绿岩中 MORB 型岩石的研究 ${ }^{2}$, 已揭示出秦岭地区存在高放射成因铅同位 素的古洋壳幔, 北秦岭基性岩的铅同位素比值与其类似. 在北秦岭南侧, 南秦岭地区 (本文所 指的是汉中 宁陕一线东部地区) 是扬子陆块的一部分, 它们的元古宙基性岩的铅同位素组成 与扬子内部是基本相同的, 可以代表扬子的区域特征. 在中国北方华北陆块与南方扬子陆块 之间, 在元古宙时存在一个由高放射成因铅同位素岩石组成的块体一一北秦岭, 明显不同于相 对低放射成因铅同位素的两侧陆块, 而与秦岭地区的蛇绿岩中的 MORB 型岩石类似, 这表明 北秦岭元古宙基性岩的高放射成因铅同位素组成可能与曾经存在的秦岭古洋壳幔有成因联 系.

北秦岭元古宙基性岩高放射成因铅同位素组成的可能原因是: 在元古宙时扬子陆块的北 侧存在高放射成因铅同位素组成的秦岭古洋壳幔, 北秦岭地区的基性岩均源于高放射成因铅

1) 许继锋. 中国地质大学博士学位论文.

2) 许继锋. 秦岭古 MORB 型岩石的高放射性铅同位素组成:特提斯型洋幔存在的证据. 中国科学(待发表) 1995 
同位素的秦岭古洋岩石圈地幔, 在此古洋壳幔基底上, 衍生形成了北秦岭地块, 所以北秦岭地 区元古宙各种岩石具有高放射成因铅同位素组成特征.

总之, 北秦岭地区不应看作是在华北陆块基底上发展形成的南部大陆边缘, 它的高放射成 因铅同位素组成可能与扬子陆块周边的秦岭古洋壳幔有关. 在华北与扬子陆块之间, 存在一 条元古宙富放射成因铅同位素组成的岩带, 它应是消失了的高放射成因铅同位素组成秦岭古 洋幔壳的残留遗迹, 可作为划分中国南北大陆界线的良好标志. 一般认为, 华北陆块可能属于 古劳亚大陆; 中国南方的华南与扬子陆块归属古冈瓦纳大陆 ${ }^{[10]}$, 若是如此, 北秦岭则可能是南 北两大古陆的分界(带).

\section{参考文献}

1 张本仁主编. 秦巴岩石圈、构造及成矿规律地球化学研究. 武汉: 中国地质大学出版社, 1994. 1 50

2 张宏飞, 赵志丹, 骆庭川等. 从岩石的 $\mathrm{Sm}-\mathrm{Nd}$ 同位素模式年龄论北秦岭地壳增生和地壳深部性质. 岩石学报, 1995, $11: 160 \sim 170$

3 Zhu B Q. Evidence of isotopic systematics from crust and mantle for chemical heterogeneities of terranes. Chinese Science Bulletin, 1991, 36:1279 1282

4 张理刚主编. 东亚岩石圈块体地质一一地唚基底和花岗岩同位素地球化学及其动力学. 北京: 科学出版社, 1995.15 $\sim 350$

5 游振东, 索书田主编. 造出带核部杂岩变质过程与构造解析. 武汉: 中国地质大学出版社, 1991. 227 233

6 张寿广,万渝生, 刘国惠等. 北秦岭宽坪群变质地质. 北京: 北京科学技术出版社, 1991. 9 54.

7 张 旗, 张宗清, 孙 勇等. 陕西商县-丹凤地区丹凤群变质玄武岩的微量元素和同位素地球化学. 岩石学报, 1995, $11: 43 \sim 54$

8 张宗清, 刘敦一, 付国民等. 北秦岭变质地层闹位素年代研究. 北京: 地质出版社, 1994. 21 165

9 陈晋锿, 泰正永, 王寿琼等. 武当群地质特征. 天津: 天津科技翻译出版公司, 1991. 41 116

10 Zhu B Q. Geochemical evidence for the southern China block being a part of Gondwana. Journal of Southeast Asian Earth Sciences, 1994, 9:319 324 